\title{
Biofunctional activities of squid milt hydrolysate
}

\author{
Wahyudi and S. M. Kim \\ Department of Marine Food Science and Technology, Gangneung-Wonju National University, Gangneung 210-702, Korea
}

Reactive oxygen species (ROS) are a toxic product of aerobic metabolism which is generated abundantly in inflammatory tissues. Oxidative stress induces the production and the release of mast cell mediators. $\mathrm{H}_{2} \mathrm{O}_{2}$ upregulates IL-4 and IL-6 genes expression and cytokine secretion through an apurinic/apyrimidinic endonulease (APE/Ref-1)-dependent pathway in mast cell ${ }^{(1)}$. Tumor necrosis factor- $\alpha$ $(\mathrm{TNF}-\alpha)$ can increase the level of ROS and activate NF- $\kappa \mathrm{B}$ which is responsible for up-regulation of matrix metalloproteinases (MMPs) $)^{(2)}$. MMPs belong to the family of neutral endopeptidases which participate in many physiological processes including tissue remodeling and inflammation. In this study, the biofunctional activities of squid milt hydrolysates on antioxidant and MMPs inhibitory activity were investigated.

Squid milt was hydrolyzed with trypsin at $50^{\circ} \mathrm{C}$ for $5 \mathrm{~h}$ in $0.05 \mathrm{M}$ phosphate buffer, $\mathrm{pH} 8$. The squid milt hydrolysate was purified using 10,5 and $3 \mathrm{kDa}$ cut-off ultrafiltration membranes. Ultrafiltration fractions were freeze-dried and further used for antioxidant and MMPs inhibitory activity assessment ${ }^{(3)}$.

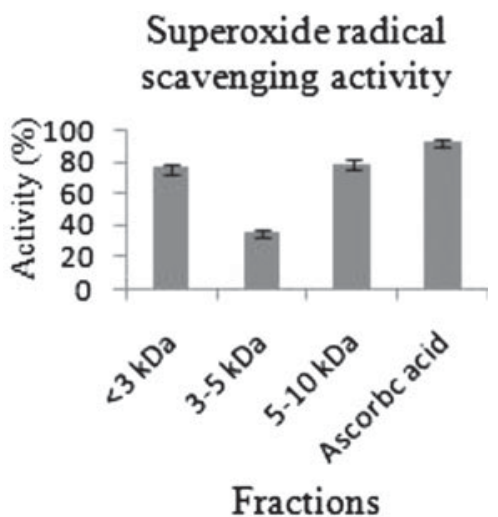

Fig. 1. Superoxide radical scavenging activity of squid milt hydrolysate $(100 \mu \mathrm{g} / \mathrm{mL})$.

\section{Hydroxyl radical scavenging activity}

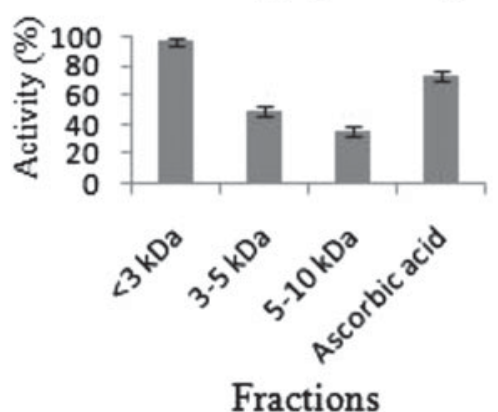

Fig. 2. Hydroxyl radical scavenging activity of squid milt hydrolysate $(100 \mu \mathrm{g} / \mathrm{mL})$.

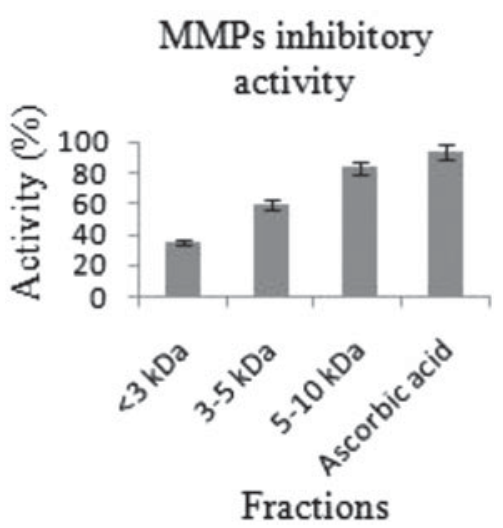

Fig. 3. MMPs inhibitory activity of squid milt hydrolysate $(100 \mu \mathrm{g} / \mathrm{mL})$

There was no significant difference between $<3 \mathrm{kDa}$ and $5-10 \mathrm{kDa}$ molecular weight of squid milt hydrolysates $(p>0.05)$ on superoxide radical scavenging activity (Fig. 1), but significantly different on hydroxyl radical scavenging activity (Fig. 2). The high molecular weight of fraction $(5-10 \mathrm{kDa})$ had highest activity on MMPs inhibition $(p<0.05)$. In conclusion, the squid milt hydrolysate with high molecular weight $(5-10 \mathrm{kDa})$ had strong antioxidant and MMPs inhibitory activity. These results may useful to promote squid milt which is fishery industry by-product as material for biofunctional food resources with the benefits as antioxidant and antiinflammation.

1. Frossi B, Carli MD, Daniel KT et al. (2003) Eur J Immunol 33, 2168-2177.

2. Song HY et al. (2011) BMB report 44, 462-467.

3. Sin BY \& Kim HP (2005) Arch Parm Res 10, 1151-1155. 